\title{
An exploratory investigation of the measurement of cognitive load on shift: Application of cognitive load theory in emergency medicine
}

Citation for published version (APA):

Vella, K. M., Hall, A. K., van Merrienboer, J. J. G., Hopman, W. M., \& Szulewski, A. (2021). An exploratory investigation of the measurement of cognitive load on shift: Application of cognitive load theory in emergency medicine. AEM Education and Training: a global journey of emergency care, 5(4), [e10634]. https://doi.org/10.1002/aet2.10634

Document status and date:

Published: 01/10/2021

DOI:

10.1002/aet2.10634

Document Version:

Publisher's PDF, also known as Version of record

Document license:

Taverne

Please check the document version of this publication:

- A submitted manuscript is the version of the article upon submission and before peer-review. There can be important differences between the submitted version and the official published version of record.

People interested in the research are advised to contact the author for the final version of the publication, or visit the DOI to the publisher's website.

- The final author version and the galley proof are versions of the publication after peer review.

- The final published version features the final layout of the paper including the volume, issue and page numbers.

Link to publication

\footnotetext{
General rights rights.

- You may freely distribute the URL identifying the publication in the public portal. please follow below link for the End User Agreement:

www.umlib.nl/taverne-license

Take down policy

If you believe that this document breaches copyright please contact us at:

repository@maastrichtuniversity.nl

providing details and we will investigate your claim.
}

Copyright and moral rights for the publications made accessible in the public portal are retained by the authors and/or other copyright owners and it is a condition of accessing publications that users recognise and abide by the legal requirements associated with these

- Users may download and print one copy of any publication from the public portal for the purpose of private study or research.

- You may not further distribute the material or use it for any profit-making activity or commercial gain

If the publication is distributed under the terms of Article 25fa of the Dutch Copyright Act, indicated by the "Taverne" license above, 


\title{
An exploratory investigation of the measurement of cognitive load on shift: Application of cognitive load theory in emergency medicine
}

\author{
Kimberly M. Vella MD, MSc ${ }^{1,2}$ @ | Andrew K. Hall MD, FRCPC, MMEd ${ }^{2}$ @ | \\ Jeroen J. G. van Merrienboer PhD ${ }^{3}$ | Wilma M. Hopman MA ${ }^{4}$ | \\ Adam Szulewski MD, FRCPC, MHPE, $\mathrm{PhD}^{5}$ ๑)
}

${ }^{1}$ Faculty of Health Sciences, Queen's University, Kingston, ON, Canada

${ }^{2}$ Department of Emergency Medicine, Queen's University, Kingston, ON, Canada

${ }^{3}$ Department of Educational Development and Research, Faculty of Health, Medicine and Life Sciences, Maastricht University, ER Maastricht, The Netherlands

${ }^{4}$ Kingston General Hospital Research Institute, Department of Public Health Sciences, Queen's University, Kingston, ON, Canada

${ }^{5}$ Departments of Emergency Medicine \& Psychology, Queen's University, Kingston, Canada

\section{Correspondence}

Adam Szulewski, MD, FRCPC, MHPE, PhD, Departments of Emergency Medicine \& Psychology, Queen's University, 76 Stuart Street, Kingston, ON K7L 2V7, Canada.

Email:aszulewski@qmed.ca

Funding information

The authors would like to thank the McLaughlin Research Studentship Fund for their generous support for funding this project.

Supervising Editor: Nicole M. Delorio, MD

\begin{abstract}
Background: Emergency physicians often experience a high cognitive load (CL) due to the inherent nature of working in acute care settings. CL has traditionally been measured in educational studies but has not been well studied in the clinical environment. Methods: Emergency medicine attending physicians and residents working in an academic urgent care center completed psychometric questionnaires while on shift to measure overall $\mathrm{CL}$, intrinsic cognitive load (ICL), extraneous cognitive load (ECL), and acute stress. Data regarding the patient load, patient acuity, and the number of patients in the waiting room were also collected. Correlational analysis and simple linear regression were used to evaluate predictors of $C L$ on shift.

Results: Forty-two questionnaires were completed ( 26 by attending physicians, 16 by residents). Attending physicians carried a significantly higher patient load compared to residents $(p<0.001)$. No differences in mean overall $C L, I C L$, ECL, and acute stress were observed between attending physicians and residents. Bivariate analysis demonstrated associations between ICL, ECL, acute stress, and overall $\mathrm{CL}$ in attending physicians. In residents, acute stress was the only variable associated with overall $\mathrm{CL}$ and the number of high-acuity patients was associated with ICL.

Conclusions: Factors influencing reported CL during clinical work are different between attending emergency physicians and residents. Further study to appreciate the impact of these differences is required and may help educators elucidate strategies to better manage $\mathrm{CL}$, thereby improving clinical performance and potentially improving patient care.
\end{abstract}

KEYWORDS

clinical medicine, cognitive load, cognitive load theory, emergency medicine, medical education, stress

Presented at the Canadian Association of Emergency Medicine Annual Conference, Halifax, Nova Scotia, Canada, May 2019, as well as the International Cognitive Load Theory 


\section{INTRODUCTION}

The dynamic and complex nature of working in acute care settings, such as the emergency department (ED), imposes a significant cognitive load $(\mathrm{CL})$ on emergency medicine (EM) physicians and trainees. ${ }^{1,2} \mathrm{CL}$ refers to the amount of cognitive resources used by working memory (WM) at any given time. ${ }^{3}$ EM physicians are at a high risk of cognitive overload because they treat multiple patients concurrently, face frequent interruptions, and must make critical decisions under time constraints. ${ }^{4}$ Excessive $\mathrm{CL}$ can overwhelm the physician's innate cognitive capacity and lead to psychological stress ${ }^{5}$ and medical errors. ${ }^{1}$ Therefore, measuring $\mathrm{CL}$ and evaluating its impact on physician performance and decision making in the ED can have implications on patient safety and physician wellness.

Cognitive load theory (CLT) provides a theoretical framework for learning based on the assumption that human WM is limited in both capacity and duration, and describes the learning processes involved in the transfer of newly acquired knowledge in WM into "cognitive schemas" within an unlimited long-term memory (see Table S1 in accompanying Supporting Information for glossary of key terms). ${ }^{3}$ Cognitive overload occurs when cognitive processing demands exceed the capacity of WM and can impair knowledge transfer and learning. ${ }^{3,6}$ Novice learners are at greater risk of cognitive overload because their cognitive schemas are not as developed as those with previous exposure to a particular task. Experts, on the other hand, have developed preexisting, or automated schemas that allow them to recall details and apply knowledge with less risk of overwhelming their WM. ${ }^{6}$

Cognitive load is thought to be composed of two main components: intrinsic cognitive load (ICL) and extraneous cognitive load $(E C L){ }^{7} I C L$ is determined by elements inherent to the task itself and reflects the complexity of the task and the learner's prior knowledge or skill. It follows that as a learner gains experience with a task, the ICL associated with that task decreases over time. ECL refers to the load not essential to the task. It is induced by the educational design of the learning task and is associated with the environmental conditions in which information is presented. So-called "germane" processes are thought to redistribute WM resources from extraneous processes to those relevant to learning by creating and automating cognitive schemas. ${ }^{8}$

The relationship between $\mathrm{CL}$ and stress during learning and task performance is complex and not fully understood. The impact of cognitive stress and/or psychological (emotional) stress on cognition is dependent on a combination of factors related to the individual, the task being performed, and the origin and intensity of stress. ${ }^{5}$ It has been proposed that mild stress can facilitate memory formation and learning when performing simple tasks or when the $\mathrm{CL}$ is not excessive. Conversely, high levels of acute stress or prolonged stress can impair performance during tasks that require complex reasoning. 5

Although CLT was originally described as a theory of learning, many parallels have started to be drawn to clinical medicine. For example, during clinical work in EM, ICL may be related to patient load, uncertainty, and the medical/social complexity of each physicianpatient encounter. ECL, on the other hand, is most likely a function of distractions, such as interruptions in the ED, poor equipment set-up, and staff conflicts. ${ }^{6,9}$ Theoretically, there are several factors that contribute to both ICL and ECL that can be studied experimentally, including physician proficiency, task difficulty, and number of interacting task elements. ${ }^{6,10}$ Though these factors have not been assessed in clinical settings, several simulation studies have demonstrated a difference in $\mathrm{CL}$ between novice and expert physicians while performing a medical task. ${ }^{11-15}$ Understanding the factors that contribute to $\mathrm{CL}$ while on the shift in attending physicians and residents could lead to the development of targeted strategies to mitigate $\mathrm{CL}$ and improve learning and performance.

To date, the application of CLT in medicine has been limited to the educational domain and has not been fully explicated in an authentic workplace setting during clinical work. The objectives of this study were to (1) assess the feasibility of measuring $C L$ and acute stress in EM attending physicians and trainees during clinical work and (2) evaluate the relative contribution of factors contributing to $\mathrm{ICL}$, ECL, and acute stress on overall $\mathrm{CL}$ using quantitative survey data.

\section{METHODS}

\section{Study setting and population}

Psychometric measures of physician CL were obtained from attending physicians and residents working at an academic urgent care center (UCC). This UCC triages approximately 53,000 patients per year of varying complexity from nonurgent to high-acuity patients and is part of a busy tertiary care center. EM-trained attending physicians (with varying levels of experience) who work regular shifts at the UCC and main ED and residents enrolled in the Royal College of Physicians and Surgeons of Canada EM program were recruited to participate in the study between July and August 2018. The UCC (as opposed to the higher-acuity ED) was selected as the study location because the bottleneck to patient care in this setting is typically physician efficiency. This is in contrast to the ED where patient care and flow are more often limited by bedspace and other ED issues that are outside the control of the individual provider. This study was approved by the institutional research ethics board (file no. 6023792). Written consent to participate in the study was obtained and participants did not receive any incentives to participate.

\section{Measurements and key outcome measures}

Psychometric measures of $C L$ were evaluated using a three-item mental effort questionnaire (see Figure S1) adapted from instruments described previously. ${ }^{16-19}$ Experts in EM and educational psychology were consulted to adapt the wording of these surveys, making them relevant to the clinical environment, and the surveys 
TABLE 1 Demographic characteristics of participants

\begin{tabular}{lll} 
& $\begin{array}{l}\text { Attending physicians } \\
(\boldsymbol{n}=\mathbf{2 6})\end{array}$ & $\begin{array}{l}\text { Residents } \\
(\boldsymbol{n}=16)\end{array}$ \\
\hline Age & $45 \pm 11$ & $29 \pm 2$ \\
\hline $\begin{array}{l}\text { Gender } \\
\text { Male }\end{array}$ & 15 & 12 \\
Female & 11 & 4 \\
\hline Years of experience as attending physician & $14 \pm 13[0,38]$ & - \\
\hline
\end{tabular}

Note: Data presented as mean \pm SD $[\min , \max ]$ and frequencies. were piloted with three attending physicians prior to study onset. Overall CL was measured using the Paas Cognitive Load Scale, which has been shown to be a valid and reliable tool. ${ }^{17,20,21}$ Case difficulty of current patient load (a hypothesized predictor of ICL) was evaluated using the Case Difficulty Scale adapted by Ayres. ${ }^{17} \mathrm{ECL}$ was evaluated using the Distraction Scale, adapted from Cierniak et al. ${ }^{18}$ to rank level of distraction. A single item tool for each measure of $\mathrm{CL}$ was selected to ensure the questionnaire could be completed quickly thereby minimizing additional stress/distraction on physicians during their clinical work due to their participation in the study.

In addition to $\mathrm{CL}$, acute stress was evaluated using the short form of the State-Trait Anxiety Inventory (STAI-6) described by Marteau and Bekker. ${ }^{22}$ STAI- 6 has been shown to be a valid measure of acute stress in adults within the general population and is comparable to the original 20 -item tool. $^{23}$

\section{Study protocol}

We sampled CL of attending EM physicians and EM residents covering shifts at the UCC at three times during the day (10 a.m. [one attending, one resident working], 1 p.m. [two attendings, one resident working], and 5 p.m. [two attendings, one resident working]) each day of the week during the study period. Resident(s) and attending physician(s) working at the UCC were asked by a research assistant to complete the three-item CL questionnaire and STAI- 6 after a brief orientation to the questionnaires. For each participant, the number of active patients and acuity of each patient was recorded at the time of $\mathrm{CL}$ assessment from the electronic patient tracking system. Case acuity was evaluated using the Canadian Triage and Acuity Scale (CTAS) on a scale from 1 to 5 ( 1 = resuscitation, 2 = emergent, 3 = urgent, 4 = less urgent, 5 = nonurgent), an internationally recognized ED triage scale. ${ }^{24}$ Patients triaged as CTAS 1 or 2 were considered "high acuity" with the remaining patients identified as "Iow acuity." The number of hours worked and patients waiting to see a physician (in the waiting room) were also collected.

\section{Data analysis}

Statistical analyses were conducted in IBM SPSS Statistics for Mac Version 25.0 (IMB Corp). Data were plotted to assess the normality of the underlying distribution.
Demographic data are presented as mean \pm SD and mean differences between attending physicians and residents were analyzed using Student's t-test. Correlational analysis between factors affecting overall CL, ICL, ECL, and acute stress are reported using Pearson's correlation coefficient. Correlation effect sizes were designated as weak (0.10-0.29), moderate (0.30-0.49), and strong $(>0.50)$ as described by Cohen. ${ }^{25}$ Simple linear regression was conducted to evaluate associations between predictors and overall CL (Paas Cognitive Load Scale), ICL (Case Difficulty Scale), ECL (Distraction Scale), and acute stress (STAI-6). The coefficient of determination $\left(R^{2}\right)$ was calculated to assess the strength of the association.

During the study period, a physician/resident may have completed the $C L$ assessment on one or more occasions. Here we present the results from responses of the participants' first questionnaire completed ( $n=42$ ) to comply with the statistical assumption of independence of observations. However, an analysis of a larger data set $(n=131)$, which includes multiple responses per participant, is presented in Supporting Information, as it may provide additional insight. Responses from participants' first questionnaire were compared with responses from subsequent questionnaires using t-test for dependent samples to assess for learning effect. Multivariable regression models were conducted with the larger data set to identify predictors of overall CL (Paas Cognitive Load Scale), ICL (Case Difficulty Scale), ECL (Distraction Scale), and acute stress (STAI-6). Variance inflation factor analysis was performed to assess for multicollinearity between predictors. All statistical tests were two-sided and differences with $p<0.05$ were considered significant. No adjustments were made for multiple comparisons.

\section{RESULTS}

A total of 42 questionnaires were completed during the study period. Twenty-six questionnaires were completed by attending physicians with a mean \pm SD level of experience of $14 \pm 13$ years. Sixteen residents (four first year, three second year, four third year, one fourth year, four fifth year) completed the questionnaires. All participants who were approached agreed to participate in the study and questionnaires were completed in less than 1 minute, suggesting that it was feasible to collect and analyze CL data during clinical work. Demographic characteristics for physician and resident groups are presented in Table 1. Fifteen questionnaires were completed at 10 a.m., 19 questionnaires at 1 p.m., and eight questionnaires at 
5 p.m. Attending physicians carried a significantly greater patient load compared with residents ( $6 \pm 2$ vs. $3 \pm 1, p<0.001$ ). There were no significant differences in the mean Paas Cognitive Load Scale ( $p=0.37)$, Case Difficulty Scale $(p=0.42)$, Distraction Scale ( $p=0.27)$, or STAI-6 $(p=0.48)$ between the two groups (see Table 2 ).

There were no differences between a participants' first response on the questionnaire and subsequent responses using parametric analyses; however, we have chosen to focus our analysis on independent participants for the main analysis in this paper. We have also included data from the larger data set of all participant responses ( $n=131$ ) in the Supporting Information for reference. The results from this larger data set are presented as hypothesis-generating.

\section{Correlational analysis}

Correlational analyses comparing overall $\mathrm{CL}$ and measures of $\mathrm{ICL}$, $\mathrm{ECL}$, and STAI- 6 in both attending physicians and residents are presented in Tables $3 \mathrm{~A}$ and $3 \mathrm{~B}$ respectively. In attending physicians, the Paas Scale (overall $\mathrm{CL}$ ) was strongly correlated with the STAI-6 (acute stress; $r=0.76, p<0.001$ ) and moderately correlated with the Case Difficulty Scale (ICL; $r=0.66, p<0.001$ ) and Distraction Scale (ECL; $r=0.51, p<0.01)$. These significant correlations were also observed within the larger data set with multiple measurements (see Supporting Information). Weak positive correlations were observed between the Case Difficulty Scale and Distraction Scale $(r=0.48, p=0.01)$ and between the Distraction Scale and STAI-6 ( $r=0.45, p=0.02)$.

In residents, a moderate positive correlation was observed between the Paas Scale and STAI-6 $(r=0.51, p=0.04)$. The Case Difficulty Scale was strongly correlated with the number of highacuity patients $(r=0.81, p<0.001)$.

\section{Simple linear regression analyses}

Simple linear regression analyses were performed to identify predictors of overall $C L, I C L, E C L$, and acute stress (see Table 4A-D, respectively) in attending physicians and residents. In attending physicians, there were significant relationships observed between

TABLE 2 Mean differences in measures of cognitive load and acute stress between attending physicians and residents based on participants' first response to the questionnaire

\begin{tabular}{lccc} 
& $\begin{array}{l}\text { Attending } \\
\text { physicians }(\boldsymbol{n}=26)\end{array}$ & $\begin{array}{l}\text { Residents } \\
(\boldsymbol{n}=16)\end{array}$ & $\boldsymbol{p}$-value \\
\hline Paas Scale & $5 \pm 1$ & $5.5 \pm 1$ & 0.37 \\
\hline Case Difficulty Scale & $4 \pm 1$ & $4 \pm 1$ & 0.42 \\
\hline Distraction Scale & $4 \pm 1$ & $4 \pm 1$ & 0.27 \\
STAl-6 & $36 \pm 12$ & $34 \pm 8$ & 0.48 \\
\hline Patient load & $6 \pm 2$ & $3 \pm 1$ & $<0.001$ \\
\hline
\end{tabular}

Note: Data presented as mean \pm SD.

Abbreviations: CL, cognitive load; STAI, State-Trait Anxiety Index. overall CL and measures of ICL (44\% of variation predicted, $\beta=0.53$ [95\% $\mathrm{Cl}=0.28$ to 0.78 ], $p<0.001), \mathrm{ECL}$ ( $26 \%$ of variation predicted, $\beta=0.52[95 \% \mathrm{Cl}=0.15-0.90], p<0.001$ ), and STAI-6 (57\% of variation predicted, $\beta=6.34$ [95\% Cl $=4.04-8.63], p<0.01$ ). In residents, STAI- 6 was the only predictor of overall CL ( $26 \%$ of variation, $\beta=6.17$ [95\% Cl $=0.20-12.14], p=0.04)$. There was a significant relationship between ICL and the number of high-acuity patients $(66 \%$ of variation, $\beta=0.68$ [95\% Cl $=0.40-0.95], p<0.001$ ).

Bivariate and multivariate analysis from a larger data set with multiple responses from participants $(n=131)$ is presented in the Supporting Information. While these violate the assumption of independence, they may provide additional insights into the associations between measures. Similar associations between overall $\mathrm{CL}, \mathrm{ICL}$, and acute stress were observed in attending physicians; however, ECL was no longer a significant predictor of these measures. The number of patients in the waiting room was a significant predictor of acute stress ( $\beta=0.43, p<0.001)$ in attending physicians, while the number of high-acuity patients continued to be a significant predictor of ICL $(\beta=0.63, \mathrm{p}=0.01)$ in residents.

\section{DISCUSSION}

In this study, we used psychometric rating scales to measure $C L$ and acute stress in EM attending physicians and residents during clinical work in an acute care setting. In addition, we examined the relationship between factors contributing to $C L$ and acute stress in both groups. Our data suggest that overall $\mathrm{CL}$ is strongly correlated with acute stress during clinical work.

Of note, there were no differences in mean overall $\mathrm{CL}, \mathrm{ICL}$, $E C L$, and acute stress between attending physicians and residents, suggesting that both groups experienced a similar subjective $\mathrm{CL}$ or needed to think equally hard during their clinical work. Attending and resident physician groups reported an average overall $\mathrm{CL}$ of 5 using the nine-point Paas Scale, which falls within the range for optimal learning and performance (score of 3-6 out of 9) as reported by Fraser et al. ${ }^{26}$ Therefore, according to psychometric measures of $\mathrm{CL}$ reported in this acute care setting, current patient case load did not appear to overwhelm limits of WM to cause significant cognitive overload. This is a significant finding as cognitive overload has been associated with unlearning, ${ }^{27}$ mental burnout, and patient errors. ${ }^{28}$

It is important to consider that though both the attending and the resident groups had similar measures of $\mathrm{CL}$, attending physicians carried a significantly higher patient load at any given time, suggesting that attending EM physicians were able to do more with the same investment of mental effort as residents. The study of expertise suggests that highly experienced clinicians possess more developed mental schemas within their long-term memory and therefore exhibit less ICL compared to novice physicians when completing tasks within their field of expertise. ${ }^{11,29}$ This allows them to carry a higher patient load (with a similar CL burden) than residents can. In our analysis, the number of high-acuity patients was associated with ICL for residents but not attending physicians. This result is not 
TABLE 3 A Pearson correlation coefficients between overall CL, ICL, ECL, and acute stress in attending physicians
TABLE 3 B Pearson correlation coefficients between overall CL, ICL, ECL, and acute stress in residents

\begin{tabular}{llll} 
& $\begin{array}{l}\text { Case Difficulty Scale } \\
(I C L)\end{array}$ & $\begin{array}{l}\text { Distraction Scale } \\
\text { (ECL) }\end{array}$ & $\begin{array}{l}\text { STAI-6 } \\
\text { (anxiety/stress) }\end{array}$ \\
\hline Paas Scale (overall CL) & $0.66^{\mathrm{a}}$ & $0.51^{\mathrm{b}}$ & $0.76^{\mathrm{a}}$ \\
\hline $\begin{array}{l}\text { Case Difficulty Scale } \\
(\mathrm{ICL})\end{array}$ & & $0.48^{\mathrm{c}}$ & 0.39 \\
\hline Distraction Scale (ECL) & & & $0.45^{\mathrm{c}}$ \\
\hline
\end{tabular}

Abbreviations: $\mathrm{CL}$, cognitive load; $\mathrm{ECL}$, extraneous cognitive load; $\mathrm{ICL}$, intrinsic cognitive load. ${ }^{\text {a }}$ Significant at the $<0.001$ level (two-tailed).

${ }^{\mathrm{b}}$ Significant at the 0.01 level (two-tailed).

${ }^{\text {c}}$ Significant at the 0.05 level (two-tailed).

\begin{tabular}{llll} 
& $\begin{array}{l}\text { Case Difficulty Scale } \\
\text { (ICL) }\end{array}$ & $\begin{array}{l}\text { Distraction Scale } \\
\text { (ECL) }\end{array}$ & $\begin{array}{l}\text { STAl-6 } \\
\text { (anxiety/stress) }\end{array}$ \\
\hline Paas Scale (overall CL) & 0.20 & -0.30 & $0.51^{\text {a }}$ \\
\hline $\begin{array}{l}\text { Case Difficulty Scale } \\
\text { (ICL) }\end{array}$ & & 0.00 & 0.38 \\
\hline Distraction Scale (ECL) & & & -0.27 \\
\hline
\end{tabular}

Abbreviations: $\mathrm{CL}$, cognitive load; $\mathrm{ICL}$, intrinsic cognitive load; $\mathrm{ECL}$, extraneous cognitive load; STAI, State-Trait Anxiety Index.

${ }^{\text {a }}$ Significant at the 0.05 level (two-tailed).

surprising as managing acute patients would be more difficult for novice physicians compared to experienced physicians with years of experience managing acutely ill patients.

The relationship between stress and CL has been well documented ${ }^{5}$ and has been shown to affect cognitive and technical performance both positively and negatively. ${ }^{30,31}$ In EM, a number of factors have been linked to stress, such as unpredictable patient volume/acuity, time urgency, vagueness or incomplete information, circadian rhythm disturbances, and lack of previous relationship with the patient. ${ }^{31}$ In our study, there were no differences between acute stress in attending and resident physicians and acute stress was a predictor of overall $\mathrm{CL}$ in both groups. In the educational domain, prolonged and intense stress is typically seen as an external factor that should be minimized to facilitate learning. However, in a professional domain like medicine, stress is intrinsic to caring for acutely ill patients and it makes sense that it should contribute to the CL of clinical work. ${ }^{8}$ Interestingly, in the larger analysis, the number of patients in the waiting room was a significant predictor of acute stress in attending physicians but not in residents. This may be explained by differences in macrocognition described by Schubert et al. ${ }^{12}$ who demonstrated that attending physicians were more likely to be concerned with patient flow and allocation of resources (including time) than novice physicians whose job it is to exclusively focus on their own patient load.

While many of the principles of CLT are applicable to the clinical realm, it is not surprising that the application of this instructional theory outside of the educational domain in which it was originally described has its limitations. From an educational perspective, the aim of CLT was to describe instructional methods to optimize CL in learners by managing ICL (i.e., avoiding overload by simplifying tasks and stimulating germane processing) and minimizing ECL. ${ }^{7}$ In traditional educational theory, overall $\mathrm{CL}$ is defined as the sum of $\mathrm{ICL}$ and ECL. Recently, a new model of CLT was proposed that includes environmental-related factors of $C L$ including: cognitive effects (i.e., uncertainty), physiological effects (i.e., stress), and affective effects (i.e., emotions). ${ }^{8}$ This new model aims to prevent negative states that impair learning and assumes that stress, uncertainty, and emotions restrict WM (by contributing to $\mathrm{ECL}$ ), thereby increasing $\mathrm{CL}$ and resulting in poor task performance. However, while this new model may be relevant in learning in the context of classroom learning environments, it does not apply in a professional domain like EM where uncertainty, emotion, and stress are inherent to the work environment (and therefore likely contribute to ICL). ${ }^{8,9}$ Therefore, strategies that help physicians manage the $\mathrm{CL}$, stress, emotion, and uncertainty inherent to patient care (rather than minimize it) are more appropriate. Theoretically, creating simulations that expose learners to clinical environments and provide mental practice in a controlled setting may lower the ICL associated with a given task and reduce uncertainty and stress when faced with that scenario during clinical work. New wellness curricula that promote stress management and provide education to deal with powerful emotions may free up WM, especially in learners. Sweller et al. ${ }^{8}$ propose collaboration in complex tasks to maximize the effective WM capacity of the team to counteract load imposed by stress, uncertainty, and emotions.

\section{LIMITATIONS}

Our study has a number of limitations. First, this is a single-center study from a busy hospital-based UCC, which limits the generalizability of these findings to other settings. In contrast to our regional ED where patient flow is often constrained by factors independent of the physician, physicians in this UCC are almost always the bottleneck to patient 


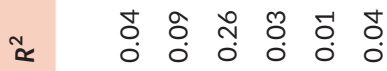

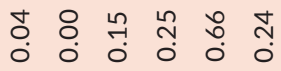

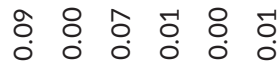

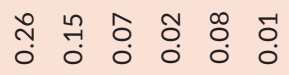

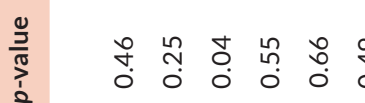

$\begin{array}{llllll}0 & -1 & 0 & 0 & 0 & 0 \\ 0 & 0 & 0 & 0\end{array}$

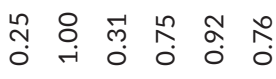

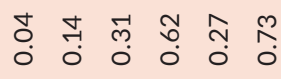

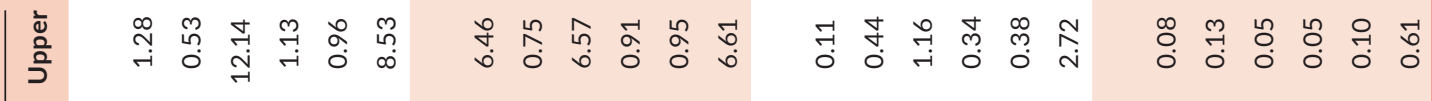

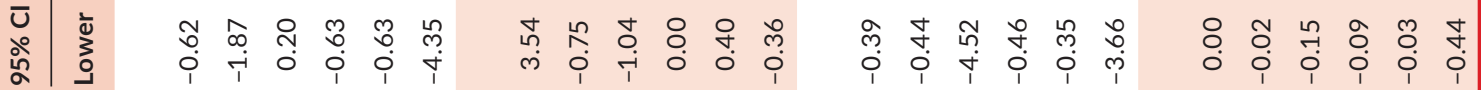

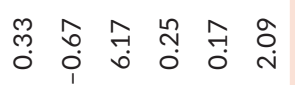

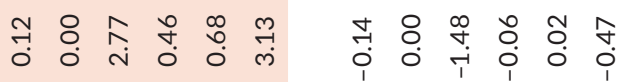

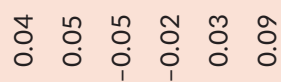

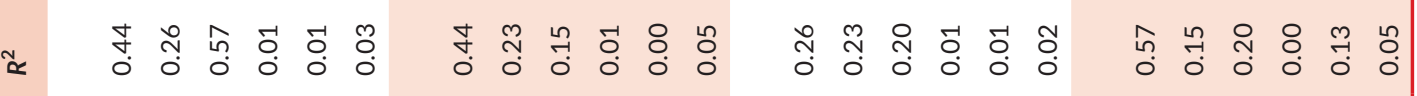

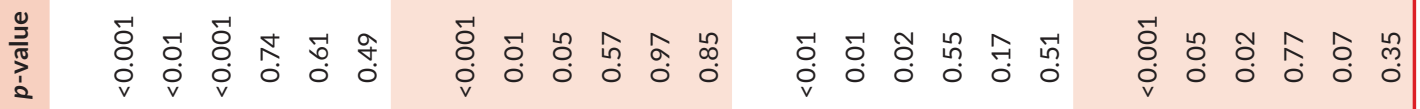

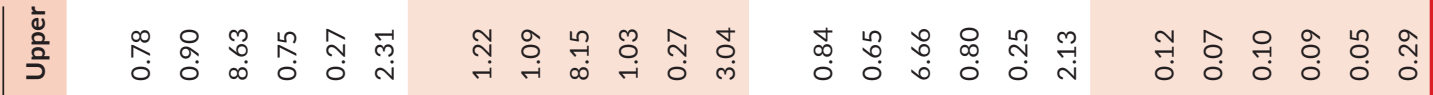

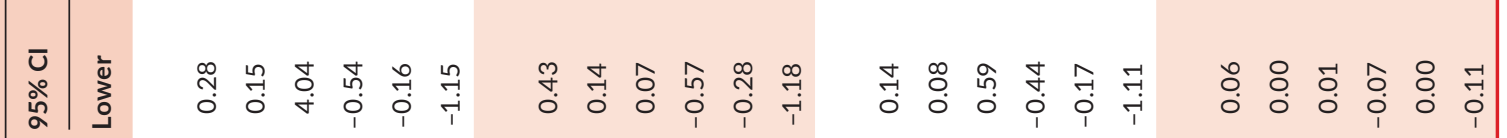

包

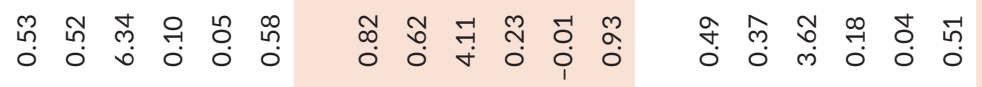

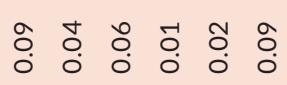

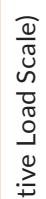

。

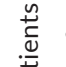

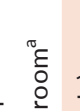

永京

نे

范 
flow. As a result, we felt that this was the ideal environment to study $\mathrm{CL}$ as physicians are generally working near their WM capacity. To ensure the feasibility of our study and limit interruption during clinical work, single-item tools were selected to evaluate the various measures of $\mathrm{CL}$ (as opposed to using multi-item tools which may have yielded richer results). Due to a limited number of participants, a convenience sample of attending physicians and residents was selected for this study, and participants completed the survey on multiple shifts. Here we presented findings from the convenience sample with participants' first response to the questionnaire. Despite the limited sample size, similar trends to those described in our analysis were observed in the Supporting Information. Results from the larger data set were included as hypothesis generating and future studies should include larger sample sizes to more fully characterize these findings. Finally, the effect of other potential confounders including emotional state, level of fatigue, and personality traits between participants was not evaluated and should be explored in future studies of $\mathrm{CL}$ in clinical settings.

\section{CONCLUSIONS}

To our knowledge, this is the first study evaluating predictors of cognitive load between attending EM physicians and residents during clinical work. Acute stress was found to be a significant predictor of overall CL. Measures of ICL and ECL predicted overall $\mathrm{CL}$ in attending physicians, while the number of high-acuity patients predicted ICL in residents. Although further study of the predictors of $\mathrm{CL}$ and acute stress on shift is required, our findings suggest that different factors contribute to $\mathrm{CL}$ and stress in experienced EM physicians compared to trainees. Appreciating these differences is critical to tailoring the clinical work environment to optimize $\mathrm{CL}$ and to develop both cognitive and educational strategies to maximize physician performance during clinical work. Ultimately, this has the potential to improve patient care.

\section{CONFLICT OF INTEREST}

The authors have no potential conflicts to disclose.

\section{AUTHOR CONTRIBUTION}

Kimberly M. Vella, Andrew K. Hall, and Adam Szulewski conceived the study, designed the protocol and obtained the research funding. Kimberly M. Vella collected the data and drafted the manuscript. Wilma M. Hopman completed the data analysis. All authors contributed interpretation of data, were involved in critical revision, and approved the final version of the manuscript.

\section{ETHICAL APPROVAL}

This study was approved by the Queen's University Faculty of Health Sciences research ethics board approved this study (EMED282-18, file no. 6023792).

\section{SITE OF INVESTIGATION}

Urgent Care Centre, Hotel Dieu Hospital, Kingston Health Sciences Centre, Kingston ON.

\section{ORCID}

Kimberly M. Vella (D) https://orcid.org/0000-0003-0526-9060

Andrew K. Hall (D) https://orcid.org/0000-0003-1227-5397

Adam Szulewski (D) https://orcid.org/0000-0002-3076-6221

\section{REFERENCES}

1. Croskerry P, Sinclair D. Emergency medicine: a practice prone to error? CJEM. 2001;3:271-276.

2. Walls RM, Hockberger RS, Gausche-Hill M. Rosen's Emergency Medicine: Concepts and Clinical Practice. 9th ed. Philadelphia, PA: Elsevier; 2018.

3. Sweller J. Cognitive load during problem solving: effects on learning. Cogn Sci. 1988;12:257-285.

4. Laxmisan A, Hakimzada F, Sayan OR, Green RA, Zhang J, Patel VL. The multitasking clinician: decision-making and cognitive demand during and after team handoffs in emergency care. Int J Med Inform. 2007;76:801-811.

5. Sandi C. Stress and cognition. Wiley Interdiscip Rev Cogn Sci. 2013;4:245-261

6. Young JQ, Van Merrienboer J, Durning S, Ten Cate O. Cognitive load theory: implications for medical education: AMEE guide no. 86. Med Teach. 2014;36:371-384.

7. Sweller J, Van Merrienboer J, Paas F. Cognitive architecture and instructional design. Educ Physiol Rev. 1998;10:251-296.

8. Sweller J, van Merrienboer JJ, Paas F. Cognitive architecture and instructional design: 20 years later. Educ Psychol Rev. 2019;31: 261-292.

9. Szulewski A, Howes D, van Merriënboer JJ, Sweller J. From theory to practice: the application of cognitive load theory to the practice of medicine. Acad Med. 2020;96:24-30.

10. van Merriënboer JJ, Sweller J. Cognitive load theory in health professional education: design principles and strategies. Med Educ. 2010;44:85-93.

11. Szulewski A, Roth N, Howes D. The use of task-evoked pupillary response as an objective measure of cognitive load in novices and trained physicians: a new tool for the assessment of expertise. Acad Med. 2015;90:981-987.

12. Schubert CC, Denmark TK, Crandall B, Grome A, Pappas J. Characterizing novice-expert differences in macrocognition: an exploratory study of cognitive work in the emergency department. Ann Emerg Med. 2013;61:96-109.

13. Sewell JL, Boscardin CK, Young JQ, ten Cate O, O'Sullivan PS. Learner, patient, and supervisor features are associated with different types of cognitive load during procedural skills training: implications for teaching and instructional design. Acad Med. 2017;92:1622-1631

14. Pawar S, Jacques T, Deshpande K, Pusapati R, Meguerdichian MJ. Evaluation of cognitive load and emotional states during multidisciplinary critical care simulation sessions. BMJ Simul Technol Enhanc Learn. 2018;4:87-91.

15. Haji FA, Khan R, Regehr G, Drake J, de Ribaupierre S, Dubrowski A. Measuring cognitive load during simulation-based psychomotor skills training: sensitivity of secondary-task performance and subjective ratings. Adv Health Sci Educ Theory Pract. 2015;20:1237-1253.

16. Paas F. Training strategies for attaining transfer of problemsolving skill in statistics: a cognitive-load approach. J Educ Psychol. 1992;84:429-434

17. Ayres P. Using subjective measures to detect variations of intrinsic load within problems. Learn Instr. 2006;16:389-400.

18. Cierniak G, Scheiter K, Gerjets P. Explaining the split-attention effect: Is the reduction of extraneous cognitive load accompanied by an increase in germane load? Comput Human Behav. 2009;25:315-324.

19. Leppink J, Paas F, Van der Vleuten CP, Van Gog T, Van Merriënboer JJ. Development of an instrument for measuring 
different types of cognitive load. Behav Res Methods. 2013;45 1058-1072.

20. Paas F, Tuovinen JE, Tabbers H, Van Gerven PW. Cognitive load measurement as a means to advance cognitive load theory. Educ Psychol. 2003;38:63-71.

21. Szulewski A, Gegenfurtner A, Howes DW, Sivilotti ML, van Merriënboer JJ. Measuring physician cognitive load: validity evidence for a physiologic and a psychometric tool. Adv Health Sci Educ Theory Pract. 2017;22:951-968.

22. Marteau TM, Bekker H. The development of a six-item short-form of the state scale of the Spielberger State-Trait Anxiety Inventory (STAI). Br J Clin Psychol. 1992;31(Pt 3):301-306.

23. Tluczek A, Henriques JB, Brown RL. Support for the reliability and validity of a six-item state anxiety scale derived from the State-Trait Anxiety Inventory. J Nurs Meas. 2009;17:19-28.

24. Bullard MJ, Melady D, Emond M, et al. Guidance when applying the Canadian Triage and Acuity Scale (CTAS) to the geriatric patient. CJEM. 2017;19:415

25. Cohen J. Statistical Power Analysis for the Behavioural Sciences. 2nd ed. Hillsdale, NJ: Erlbaum; 1988.

26. Fraser KL, Ayres P, Sweller J. Cognitive load theory for the design of medical simulations. Simul Healthc. 2015;10:295-307.

27. Crossley MJ, Maddox WT, Ashby FG. Increased cognitive load enables unlearning in procedural category learning. J Exp Psychol Learn Mem Cogn. 2018;44:1845-1853.

28. Young JQ, ten Cate O, O'Sullivan PS, Irby DM. Unpacking the complexity of patient handoffs through the lens of cognitive load theory. Teach Learn Med. 2016;28:88-96.
29. Young JQ, van Dijk SM, O'Sullivan PS, Custers EJ, Irby DM, ten Cate O. Influence of learner knowledge and case complexity on handover accuracy and cognitive load: results from a simulation study. Med Educ. 2016;50:969-978.

30. Wong ML, Anderson J, Knorr T, Joseph JW, Sanchez LD. Grit, anxiety, and stress in emergency physicians. Am J Emerg Med. 2018;36:1036-1039

31. Lauria MJ, Gallo IA, Rush S, Brooks J, Spiegel R, Weingart SD. Psychological skills to improve emergency care providers' performance under stress. Ann Emerg Med. 2017;70:884-890.

32. Koolhaas JM, Bartolomucci A, Buwalda B, et al. Stress revisited a critical evaluation of the stress concept. Neurosci Biobehav Rev. 2011;35:1291-1301.

\section{SUPPORTING INFORMATION}

Additional supporting information may be found online in the Supporting Information section.

How to cite this article: Vella KM, Hall AK, van Merrienboer JJG, Hopman WM, Szulewski A. An exploratory investigation of the measurement of cognitive load on shift: Application of cognitive load theory in emergency medicine. AEM Educ

Train. 2021;5:e10634. https://doi.org/10.1002/aet2.10634 